\title{
GAISE 2016 PROMOTES STATISTICAL LITERACY
}

\author{
MILO SCHIELD \\ Augsburg College \\ Schield@Augsburg.edu
}

\begin{abstract}
In the 2005 Guidelines for Assessment and Instruction in Statistics Education (GAISE), statistical literacy featured as a primary goal. The 2016 revision eliminated statistical literacy as a stated goal. Although this looks like a rejection, this paper argues that by including multivariate thinking and - more importantly - confounding as recommended topics in introductory statistics, statistical literacy has in fact been accepted if not promoted. The adoption of the new guidelines will greatly advance students' statistical literacy: the ability to read and interpret statistics relevant to consumers and decision makers.
\end{abstract}

Keywords: Statistics education, Multivariable relationships, Confounding

RISE AND FALL OF STATISTICAL LITERACY

Statistical literacy has a long history among statisticians and statistical educators. Between 1951 and 2000, at least 11 books and 78 articles refer to statistical literacy (Schield, 2017). Since then the number of posters, papers, topic sessions and entire conferences dedicated to statistical literacy is over-whelming. The focus on statistical literacy arguably peaked with the American Statistical Association's (ASA) Guidelines for Assessment and Instruction in Statistics Education (GAISE, 2005). The College Report's \#1 recommendation is "emphasize statistical literacy and develop statistical thinking" while the PreK-12 report proclaimed "The ultimate goal: statistical literacy."

The demise of statistical literacy seems most evident in the 2016 revision to these guidelines. The revision dropped support for statistical literacy by changing the first recommendation from "emphasize statistical literacy and develop statistical thinking" to "emphasize statistical thinking." The Everson committee (2015) justified this omission:

It appears that some feel the original recommendation to 'emphasize statistical literacy and statistical thinking' might be too confusing and might appear to get at two very different things. There is concern that not everyone may understand what is meant by 'statistical literacy' and 'statistical thinking'. We could add some text to define each term [...], but this would yield a recommendation that is quite long [...]. (p. 1).

This demise may have been foreshadowed by Rumsey (2002) who said "the use of the phrase 'statistical literacy' is too broad. I will attempt to clarify the issues by omitting the phrase 'statistical literacy' from my discussion, [...]." Does this imply that "statistical literacy" is officially rejected? And if so, is the 2016 GAISE committee willing to discourage hundreds - if not thousands - of statistical educators from continuing their work involving statistical literacy? Is this committee about to ignore the support for statistical literacy so evident in the original GAISE guidelines? I say "No!" This GAISE revision committee has noted the most obvious fact about statistical literacy: the difficulty to agree on a generally-accepted definition.

Statistics Education Research Journal, 16(1), 50-54, http://iase-web.org/Publications.php? $p=S E R J$

(C) International Association for Statistical Education (IASE/ISI), May, 2017 - Invited essay 


\section{DIFFICULTY DEFINING STATISTICAL LITERACY}

So why have statistical educators been unable to agree on a definition of statistical literacy? One reason is that there are several different kinds of definitions. Walker (1951) provided a language-based definition: "the social scientists' ability to use quantitative language." Wallman (1993) provided an activity-based definition: "the ability to understand and critically evaluate the statistical results that permeate daily life, coupled with the ability to appreciate the contributions that statistical thinking can make in public and private, professional and personal decisions." Moore (1998) used an audience-based definition: "Statistical literacy: what every educated person should know." Schield (1999) used a critical-thinking based definition: "the ability to think critically about statistics as evidence in arguments". The 2005 GAISE College Report used a content-based definition: "We define statistical literacy as understanding the basic language of statistics (e.g., knowing what statistical terms and symbols mean and being able to read statistical graphs) and fundamental ideas of statistics." Gal (2002) used a role-based definition: "people's ability to act as effective 'data consumers' in [...] reading [non-enquiry] contexts." Ben Zvi and Garfield (2004) used thinking-based definitions to distinguish statistical literacy (SL), statistical reasoning (SR) and statistical thinking (ST). Broers (2006) argued that "their existence is not dictated by empirical observations" so "the inherent ambiguity of the three concepts makes them unsuitable as learning goals for statistics education."

But why are there so many different kinds of definitions? Perhaps it is because statistical literacy involves two words. In most two-word descriptions of a discipline, one word is dominant. In some cases, the noun is dominant: organic chemistry and medieval history. In other cases the adjective is dominant: computer literacy, digital literacy, information literacy, media literacy, visual literacy and cultural literacy. In the case of statistical literacy, there is no agreement on whether literacy is primary or secondary. In summary, the phrase 'statistical literacy' continues to have 'issues'. It is not surprising that statistical educators have been unable to agree on a definition for statistical literacy. Given the lack of agreement, the GAISE revision committee may have been very wise in avoiding any attempt to define statistical literacy.

\section{DID THE GAISE 2016 UPDATE REJECT STATISTICAL LITERACY?}

But is the GAISE 2016 revision responsible for the demise of statistical literacy? Has statistical literacy been officially rejected? I say "Not at all!" There is evidence abundant evidence - in the same document that the GAISE 2016 revision has actually accepted - and encouraged - statistical literacy. Their official recommendation has done more to advance the cause of statistical literacy than any previous paper, book, group or committee. Statistical literacy may have lost a battle as a phrase, but it may be winning the war as an idea. It all depends on how one defines statistical literacy.

Consider these definitions: As a skill, statistical literacy is the ability to read and interpret those statistics most relevant for consumers and decision makers. As a discipline statistical literacy studies the meaning of - and influences on - those statistics most relevant to consumers and decision makers. According to Tintle et al. (2013), a main topic is "identifying the two major themes of statistical analysis (confounding and variation)" (p. 298). Utts (2003) noted that "it is important for students of statistics to understand the distinction between randomized experiments and observational studies, and to understand how the potential for confounding variables limits the conclusions that 
can be made from observational studies" (p. 75). In order to study confounding, one must study multivariate data.

So what does the GAISE revision (GAISE, 2016) say about multivariate thinking and confounding?

- Give students experience with multivariable thinking (p. 3).

- [Students should] have an appreciation that the relationship between two variables may depend on other variables. Multivariable relationships, illustrating Simpson's Paradox or investigated via multiple regression, help students discover that a twoway table or a simple regression line does not necessarily tell the entire (or even an accurate) story of the relationship between two variables (pp. 10).

- With large datasets $[\ldots]$ from observational studies, understanding of confounding [...] becomes even more relevant (p. 11).

- [...] how confounding plays an important role in determining the appropriate scope of conclusions to be drawn from such data (p. 15).

- that students obtain a clear understanding of principles of statistical design and tools to assess and account for the possible impact of other measured and unmeasured confounding variables (p. 34).

- Perhaps the best place to start is to consider how a third variable can change our understanding of the relationship between two variables (p. 34).

- Statistical thinking with an appreciation of Simpson's paradox would alert a student to look for the hidden confounding variables (p. 38).

\section{THE BIGGEST CHANGE}

Those reading the new GAISE report (GAISE, 2016) may not realize how big of a change this revision is. Multivariate thinking and confounding were not even mentioned in the earlier report (GAISE, 2005), neither in McKenzie's (2004) list of core concepts, nor in articles on statistical literacy by Watson (2003) and Gal (2002). But in the new version, multivariate and multivariable are mentioned 19 times and have a separate appendix. This is a big change. Simpson's paradox is mentioned six times while variations on confound are mentioned 20 times. Mentioning Simpson's Paradox and confounding is a much bigger change.

Statistical educators seem more comfortable dealing with multivariate than they are with confounding. In the entire JSM Program Book (2015), multivariate was mentioned in 14 papers; confound was mentioned in only one (which was by Schield).

Why this difference? Confounding is not a major issue in describing or predicting in the absence of a controlled intervention. Adding another predictor seldom decreases Rsquared in an ordinary least-squares regression even if it results in a change in magnitude or sign for an existing coefficient. If the goal is just prediction, the size of the predictor coefficients is almost irrelevant compared to getting a higher R-squared. But the size and sign of a predictor coefficient are major issues when explaining an association or in using observational data as evidence for causation. In explaining, confounding is a major problem.

Focusing on confounding takes statistical education much closer to causation. Avoiding confounding allows statisticians to keep their 'heads in the clouds' and avoid dealing with the causal connections in the real world. If the goal of statistical literacy is to introduce citizens and decision-makers to the uses of - and influences on - a statistic, then statistical literacy must include confounding and the many ways confounders can be taken into account. 


\section{RECENT DEVELOPMENTS}

By including confounding, the GAISE (2016) revision upholds Moore's (2001) claim that statistical literacy should focus on the difference between experiments and observational studies and teach students to "beware the lurking variable."

Schield (2016a) argued that the revised guidelines supported - if not required - a new course, STAT 102: Social Statistics for Decision Makers, with a focus on confounding and the many devices used to take into account related factors. He argued that it takes time - weeks and months, not hours or days - for students to learn to think hypothetically about what might confound an observed association. When presented at the IASE Roundtable in Berlin, most attendees agreed that statistical educators should support offering a STAT 102 course along with STAT 100 (Statistical Literacy for Consumers) and STAT 101 (Inferential Statistics for Researchers).

According to Schield (2016b), 61\% of the students taking a STAT 102 compliant course at Augsburg College in the last two years agreed that it "should be required by all college students for graduation" $(n=105)$. These same students ranked confounding and hypothetical thinking as second among the most-important topics.

It appears that statistical educators and students see value in focusing more on multivariate data and confounding in an introductory statistics course.

\section{CONCLUSIONS}

By introducing multivariate thinking and, more importantly, confounding, the GAISE revision committee has accepted - and greatly advanced - statistical literacy in the process. The revised guideline (GAISE, 2016) is the most important institutional paper advancing statistical literacy to date. Including multivariate thinking and confounding in introductory statistics courses and textbooks will be the biggest change in statistical education in decades. These are exciting times for statistical literacy and for statistics education.

\section{ACKNOWLEDGEMENTS}

Thanks to James Nicholson and Jim Ridgway for their helpful suggestions, to Tom Burnham and Marc Isaacson for their comments, and most importantly, to Manfred Borovenik for his detailed review and his helpful suggestions.

\section{REFERENCES}

Ben Zvi, D. \& Garfield, J. (2004). Statistical literacy, reasoning, and thinking: goals, definitions, and challenges. In D. Ben-Zvi \& J. Garfield (Eds.), The challenge of developing statistical literacy, reasoning, and thinking (pp. 3-15). Dordrecht, The Netherlands: Kluwer Academic Publishers.

Broers, Nick (2006). Learning goals: The primacy of statistical knowledge. In A. Rossman $\&$ B. Chance (Eds.), Proceedings of the Seventh International Conference on Teaching Statistics. [Online: iase-web.org/Conference_Proceedings.php?p=ICOTS_7_2006]

Everson (2015). Updating the guidelines for assessment and instruction in statistics education. College Report. [Online: www.statlit.org/pdf/2015-GAISE-Update-Survey.pdf]

GAISE (2005). Guidelines for assessment and instruction in statistics education. PreK-12 and College report. Alexandria, VA: American Statistical Association. 
[Online: www.amstat.org/asa/education/Guidelines-for-Assessment-and-Instructionin-Statistics-Education-Reports.aspx]

GAISE (2016). Guidelines for assessment and instruction in statistics education. College report. Alexandria, VA: American Statistical Association.

[Online: www.amstat.org/asa/files/pdfs/GAISE/GaiseCollege_Full.pdf]

Gal, I. (2002). Adults' statistical literacy: Meanings, components, responsibilities (with discussion and a rejoinder by the author). International Statistical Review, 70(1), 1-51. [Online: iase-web.org/Publications.php?p=Int_Stat_Review]

JSM Program Book (2015). Joint Statistical Meetings Seattle. American Statistical Association. [Online: ww2.amstat.org/MembersOnly/proceedings/2015/]

McKenzie, J. D. Jr. (2004). Conveying the core concepts. In Papers presented at the Joint Statistical Meetings Toronto (pp. 2755-2757).

[Online: www.statlit.org/pdf/2004McKenzieASA.pdf]

Moore, D. (1998, March). Statistical literacy and statistical competence in the $21^{\text {st }}$ century. Presentation at the Joint Illinois-Purdue Statistics Colloquium.

[Online: www.math.uiuc.edu/Bulletin/Abstracts/March/mar13-98jointstat.html]

Moore, D. (2001, August). Statistical literacy and statistical competence. Presentation at the IASE Satellite on Statistical Literacy, Seoul, Korea.

[Online: iase-web.org/Conference_Proceedings.php?p=Stat_Literacy_2001]

Rumsey, D. J. (2002). Statistical literacy as a goal for introductory statistics courses. Journal of Statistics Education, 10(3).

[Online: ww2.amstat.org/publications/jse/jse_archive.htm]

Schield, M. (1999). Statistical literacy: thinking critically about statistics. Of Significance ..., 1(1), 15-20. [Online: www.statlit.org/pdf/1999SchieldAPDU.pdf]

Schield, M. (2016a). Offering STAT 102: Social Statistics for Decision Makers. In J. Engel (Ed.), Promoting understanding of statistics about society. Proceedings of the IASE Roundtable Conference. [Online: iase-web.org/Conference_Proceedings.php]

Schield, M. (2016b). Augsburg student evaluations of STAT 102: Social Statistics for Decision Makers. In Papers presented at the Joint Statistical Meetings Chicago, IL (pp. 3741-3750). [Online: www.StatLit.org/pdf/2016-Schield-ASA.pdf]

Schield, M. (2017). A history of statistical literacy. Technical Report. [Online: www.StatLit.org/StatLitHistory.htm]

Tintle, N. L., Chance, B., Cobb, G., Rossman, A., Roy, S. Swanson, T., \& VanderStoep, J. (2013). Challenging the state of the art in post-introductory statistics: preparation, concepts, and pedagogy. In Proceedings of the $59^{\text {th }}$ World Statistics Congress (pp. 295-300). [Online: 2013.isiproceedings.org/]

Utts, J. (2003). What educated citizens should know about statistics and probability. The American Statistician, 57(2), 74-79. [Online: www.ics.uci.edu/ jutts/AmerStat2003.pdf]

Wallman, K. K. (1993). Enhancing statistical literacy: enriching our society. Journal of the American Statistical Association, 88(421), 1-8.

[Excerpts Online: www.statlit.org/StatLitHistory.htm]

Walker, H. M. (1951). Statistical literacy in the social sciences. The American Statistician, 5(1) 6-12. [Excerpts Online: www.statlit.org/StatLitHistory.htm]

MILO SCHIELD

150 Front St., Unit 411

Prescott, Wisconsin 54021

USA 